\title{
Структурные и фотоэлектрические свойства тонких пленок оксида цинка на подложке танталата лития
}

\author{
(C) Л.В. Григорьев ${ }^{1,2}$, А.А. Семенов ${ }^{2}$, А.В. Михайлов ${ }^{3}$ \\ ${ }^{1}$ Санкт-Петербургский государственный университет, \\ 199034 Санкт-Петербург, Россия \\ ${ }^{2}$ Санкт-Петербургский государственный электротехнический университет „ЛЭТИ“, \\ 197022 Санкт-Петербург, Россия \\ ${ }^{3}$ АО „гГИ им. С.И. Вавилова“, \\ 199054 Санкт-Петербург, Россия \\ E-mail: Ivgrigoryev@mail.ru
}

Поступила в Редакцию 27 июля 2021 г.

В окончательной редакции 2 августа 2021 г.

Принята к публикации 2 августа 2021 г.

Представлены результаты исследования структурных и фотоэлектрических свойств тонкопленочной структуры $\mathrm{ZnO}-\mathrm{LiTaO}_{3}$. Приведены результаты рентгеноструктурного анализа и данных атомно-силовой микроскопии для пленок оксида цинка, синтезированных на подложке из монокристаллического танталата лития и на подложке из полированного кварца КУ-1. Приведена спектральная зависимость фотоэлектрического тока тонкопленочной структуры $\mathrm{ZnO}-\mathrm{LiTaO}_{3}$ и структуры $\mathrm{ZnO}-$ кварц в ультрафиолетовом и видимом диапазонах спектра. Представлены результаты восстановления методом регуляризации Тихонова-Лаврентьева энергетического спектра оптически активных дефектов, присутствующих в структуре $\mathrm{ZnO}-\mathrm{LiTaO}_{3}$.

Ключевые слова: тонкие пленки, оксид цинка, лазерная абляция, сегнетоэлектрические материалы, фотопроводимость, рентгеноструктурный анализ, атомно-силовая микроскопия, регуляризация ТихоноваЛаврентьева.

DOI: $10.21883 /$ FTP.2021.12.51703.9724

\section{1. Введение}

Тонкопленочные структуры полупроводник-сегнетоэлектрик в настоящее время привлекают большое внимание исследователей благодаря возможности создания на их основе устройств радиофотоники, фотоэлектроники, акустоэлектроники, акустооптики и функциональной электроники [1-3]. Одним из перспективных полупроводниковых материалов для таких устройств являются тонкие пленки пьезополупроводников, таких как $\mathrm{ZnO}$, $\mathrm{CdS}, \mathrm{AlN}$. Пленки оксида цинка $(\mathrm{ZnO})$ относятся к широкозонным и прямозонным полупроводникам и благодаря малым оптическим потерям и наличию большой ширины запрещенной зоны, которая при комнатной температуре составляет $\sim 3.3$ эВ, находят широкое применение в качестве активного материала для микроприборов фотоники и микроэлектроники, работающих в ультрафиолетовом и видимом диапазонах спектра $[4,5]$.

$\mathrm{B}$ этой связи структура $\mathrm{ZnO}-\mathrm{LiTaO}_{3}$ позволяет создавать оптически или электрически управляемые структуры по топологии полевого транзистора или фоторезистора с полевым управлением [6]. Для создания таких микроприборов необходимо проведение комплексного исследования структурных и фотоэлектрических свойств тонких пленок оксида цинка в составе структуры пьезополупроводник-сегнетоэлектрик. Настоящая статья является продолжением цикла проводимых работ по исследованию структуры $\mathrm{ZnO}$-сегнетоэлектрик [7-9].
В работе представлены результаты исследования структурных и фотоэлектрических свойств тонких пленок оксида цинка в составе тонкопленочных структуры $\mathrm{ZnO}$-танталат лития $\left(\mathrm{ZnO}-\mathrm{LiTaO}_{3}\right)$ и структуры тонкая пленка $\mathrm{ZnO}-$ кварц $\left(\mathrm{ZnO}-\mathrm{SiO}_{2}\right)$.

\section{2. Изготовление образцов}

Тонкопленочные структуры создавались методом лазерной абляции мишени из прессованного порошка $\mathrm{ZnO}$, марки ОСЧ [10-12]. Структуры из тонкой пленки $\mathrm{ZnO}$, нанесенной на кварцевую подложку $\left(\mathrm{ZnO}-\mathrm{SiO}_{2}\right)$, были созданы на поверхности пластин из кварца марки КУ-1. Все использованные в работе подложки были отполированы по 14 классу. Процесс формирования тонких пленок $\mathrm{ZnO}$ методом лазерной абляции проводился в импульсном режиме. Для исключения расплавления мишени из спрессованного порошка $\mathrm{ZnO}$ и сопутствующего этому разбрызгивания крупных капель расплава на подложку, а также исключения прожига мишени в процессе напыления осуществлялось сканирование лазерного луча по поверхности мишени. Рабочий объем реактора из нержавеющей стали, в котором проводился синтез пленок оксида цинка, откачивался с помощью двухконтурной безмасляной системы откачки до остаточного давления, не превышающего 0.01 Па. Для реализации процесса импульсной лазерной абляции был использован импульсный DPSS Nd:YAG-лазер, работа- 
ющий на основной длине волны генерации, составляющей 1064 нм. DPSS-лазер работал в режиме генерации гигантских импульсов, для создания которых была модифицирована схема резонатора промышленного лазера, в которую нами был введен внутрирезонаторный электрооптический модулятор. Частота следования импульсов лазера могла варьироваться в течение процесса нанесения пленки от 70 до 20 Гц. Энергия импульса лазерного излучения составляла 640 мДж. Длительность импульса лазерного излучения находилась в диапазоне 10-12 нс. Коллимированный поток лазерного излучения вводился в объем реакционной камеры через сапфировое окно. Лазерное излучение фокусировалось на поверхность мишени из $\mathrm{ZnO}$ в пятно, диаметр которого не превышал 540 мкм. Распределение мощности лазерного излучения по сечению пучка описывалось функцией Гаусса. Температура подложки из танталата лития или кварца измерялась с помощью термопары. Температура подложки в зависимости от режима напыления находилась в температурном диапазоне от комнатной до от $250^{\circ} \mathrm{C}$, что гарантировало сохранение сегнетоэлектрической фазы подложки из монокристаллического танталата лития. Нагрев сегнетоэлектрической подложки осуществлялся с помощью освещения подложки ИК-лампой. Толщина пленки $\mathrm{ZnO}$ в процессе ее роста на подложке регистрировалась с помощью кварцевых микровесов.

В работе были сформированы два типа образцов, для структурных исследований были созданы квадратные области из $\mathrm{ZnO}$ со стороной $25 \mathrm{MM}$, а для исследования фотоэлектрических свойств были сформированы полоски шириной 1.5 мм, длиной 5 мм и толщиной 3.0 мкм.

\section{3. Экспериментальные результаты}

Рентгеноструктурные исследования пленок оксида цинка проводились на дифрактометре ДРОН-3М. Для исследований использовалось излучение $\mathrm{Cu} K_{\alpha}$ с длиной волны, равной 1.5418 А.

Сравнение дифрактограмм структур оксид цинкакварц, оксид цинка на поверхности танталата лития при температуре $250^{\circ} \mathrm{C}$ и оксид цинка на поверхности подложки из танталата лития без предварительного нагрева приведены на рис. 1, $a-c$. По данным рентгеноструктурного анализа, во всех случаях синтезируемые пленки имеют нанокристаллическую структуру. Размеры кристаллов $\mathrm{ZnO}$ в объеме тонкой пленки оксида цинка, в структуре $\mathrm{ZnO}-\mathrm{LiTaO}_{3}$, вычисленные по формуле Селякова-Шеррера [13], не превышали 16 нм, а размеры нанокристаллов в слое $\mathrm{ZnO}$, нанесенного на кварцевую подложку, не превышали 12 нм.

На дифрактограммах всех синтезированных пленок оксида цинка присутствует дифракционный максимум гексагонального $\mathrm{ZnO}(002)$ большой интенсивности. Поэтому можно утверждать о наличии в синтезируемых методом импульсной лазерной абляции пленках высокого структурного совершенства. Кроме того, сле-
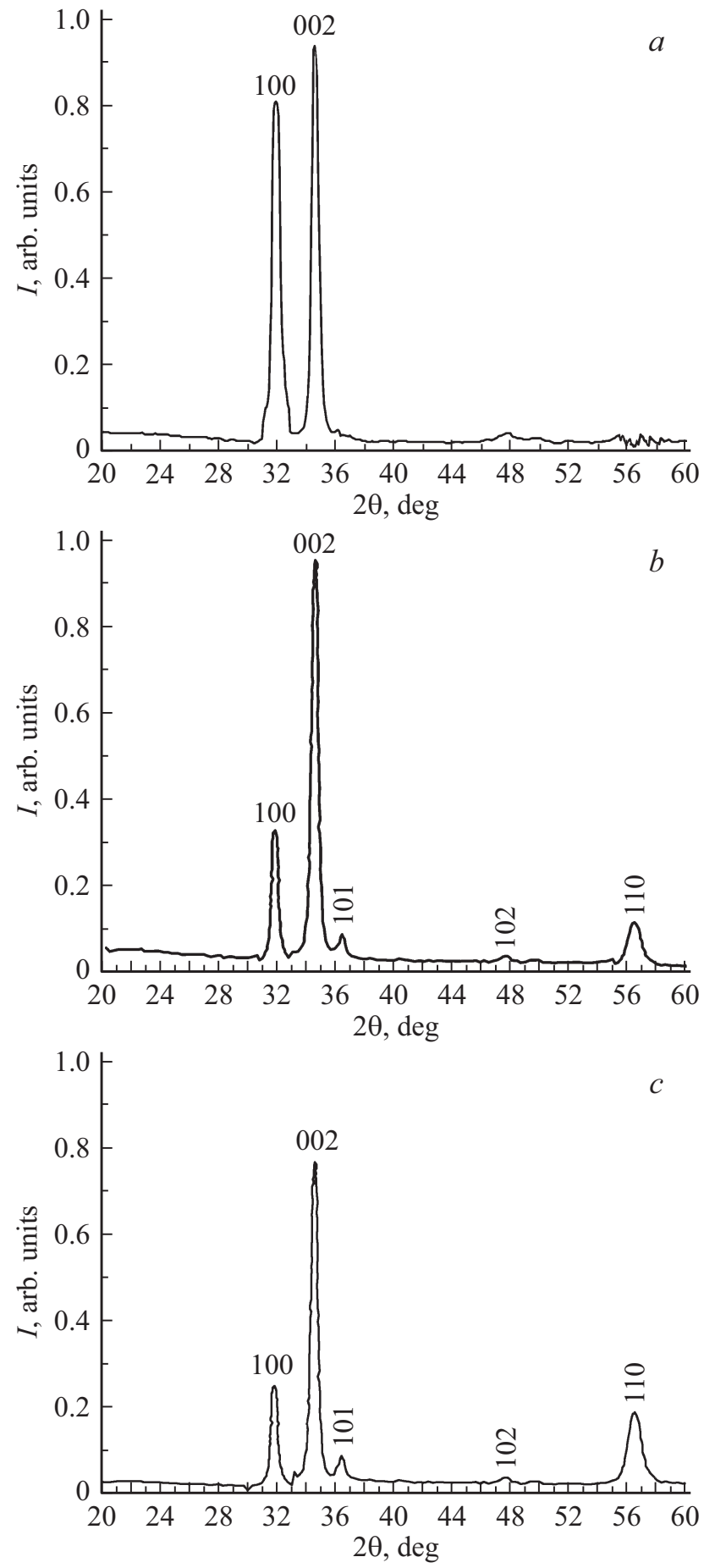

Рис. 1. $a-$ дифрактограмма тонкой пленки $\mathrm{ZnO}$ в структурах $\mathrm{ZnO}-$ кварц; $b-$ рентгенограмма поликристаллической пленки оксида цинка, синтезированной на предварительно нагретой подложке $\mathrm{LiTaO}_{3} ; c-$ рентгенограмма поликристаллической пленки оксида цинка, синтезированной на холодной подложке из $\mathrm{LiTaO}_{3}$.

дует отметить наличие выделенной осевой текстуры в направлении оси с, которая расположена перпендикулярно к поверхности подложки. У пленки оксида цинка, синтезированной на поверхности танталата лития 
с предварительным нагревом (рис. $1, b$ ), в сравнении положения пиков дифрактограммы пленок, синтезированных на кварцевой подложке (рис. 1,a), наблюдается уменьшение интенсивности пика (100) с уровня 0.8 до величины 0.33. Угловое положение пиков (100) и (002) не изменяется, что свидетельствует об отсутствии сжатия или растяжения пленки оксида цинка при ее синтезе на нагретой подложке из танталата лития. На дифрактограммах (см. рис. $1, b$ и $c$ ) пленок $\mathrm{ZnO}$, сформированных на горячей или холодной сегнетоэлектрической подложке, присутствуют рефлексы (101), (110), которые отсутствуют на дифрактограмме пленки оксида цинка, созданной на поверхности кварцевой пластины. Очень слабый рефлекс (102) в области угла $48^{\circ}$ присутствует на дифрактограммах всех исследуемых нами пленок. Интенсивность этого рефлекса неизменна независимо от типа используемой подложки или температуры подложки. Следует отметить, что интенсивность рефлекса (100) у пленки, синтезированной на подложке из $\mathrm{LiTaO}_{3}$ без предварительного нагрева, уменьшилась на $13 \%$ относительно интенсивности аналогичных пиков (рефлексов) дифрактограмм пленок, синтезированных на предварительно нагретой подложке $\mathrm{LiTaO}_{3}$, и уменьшилась на 57\% относительно интенсивности рефлекса для пленок, сформированных на кварцевой подложке. В свою очередь интенсивность пика (002) на дифрактограммах, соответствующих синтезированной пленке на кварцевой подложке и на предварительно нагретой подложке из $\mathrm{LiTaO}_{3}$, осталась без изменений. Для случая синтеза пленки оксида цинка на холодной подложке из $\mathrm{LiTaO}_{3}$ интенсивность пика (002) стала меньше на $15 \%$ в сравнении с интенсивностью аналогичного рефлекса для случая пленки, синтезированной на горячей подложке из $\mathrm{LiTaO}_{3}$ или из кварца. Рефлекс (101) малой интенсивности на дифрактограмме пленки, синтезированной на кварцевой подложке, в окрестности $36^{\circ}$, на дифрактограммах пленок $\mathrm{ZnO}$, синтезированных на сегнетоэлектрической подложке из $\mathrm{LiTaO}_{3}$, сдвинут в сторону больших углов на $1.3^{\circ}$ и возрастает по интенсивности в 2 раза для случая синтеза пленки $\mathrm{ZnO}$ на нагретой подложке и увеличивается в 3.6 раза для случая синтеза на холодной подложке. Рефлекс (110), отсутствующий на дифрактограмме для пленки $\mathrm{ZnO}$, сформированной на кварцевой подложке, появляется в окрестности угла $56^{\circ}$ на дифрактограммах пленок $\mathrm{ZnO}$, созданных на подложках $\mathrm{LiTaO}_{3}$. Интенсивность этого пика возрастает, когда пленка оксида цинка растет на холодной подложке, и она в 1.8 раза больше аналогичного пика для случая создания пленки оксида цинка на предварительно нагретой подложке танталата лития.

Сравнение литературных данных по виду дифрактограмм для пленок оксида цинка, синтезированных методом магнетронного распыления мишени из $\mathrm{ZnO}$ [14-18], с результатами рентгеноструктурного анализа, соответствующего пленкам оксида цинка, синтезированным методом импульсной лазерной абляцией на горячей и холодной подложках из танталата лития, позволяет

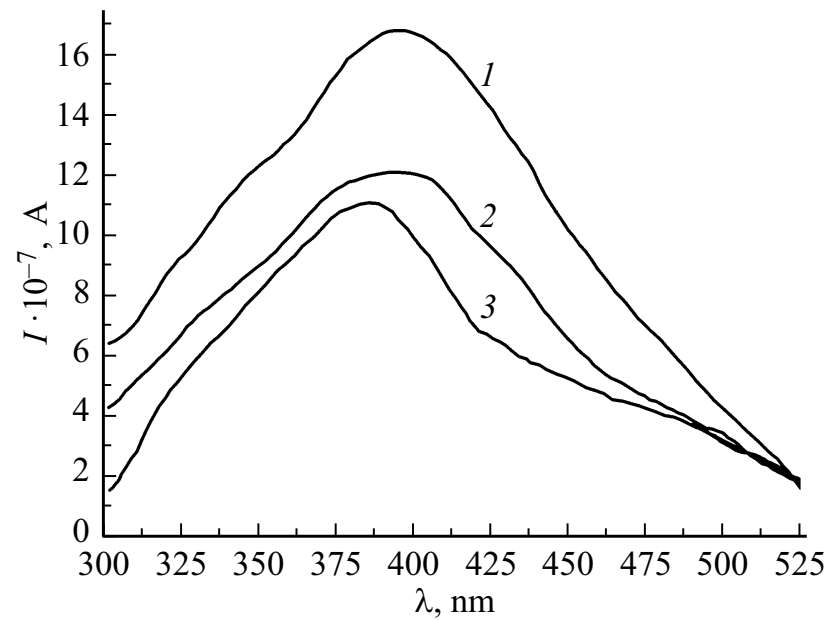

Рис. 2. Спектральная зависимость тока фотопроводимости для структур $\mathrm{ZnO}-\mathrm{LiTaO}_{3}$ и $\mathrm{ZnO}-$ кварц: $1-\mathrm{ZnO}$ нанесен на нагретую подложку $\mathrm{LiTaO}_{3} ; 2-\mathrm{ZnO}$ нанесен на холодную подложку $\mathrm{LiTaO}_{3} ; 3-\mathrm{ZnO}$ нанесен на подложку из кварца.

утверждать о хорошем совпадении значений интенсивности для рефлексов (100) и (002). Кроме того, угловое положение рефлексов (100) и (002) для всех случаев синтезированных нами пленок оксида цинка хорошо коррелирует с литературными данными [15-18]. Совместный анализ вида дифрактограмм синтезированной пленки оксида цинка методом импульсной лазерной абляции распыления высокочистой мишени из прессованного порошка $\mathrm{ZnO}$ и дифрактограмм для случая магнетронного распыления мишени из $\mathrm{ZnO}$ [4,14-16] показал отсутствие дифракционных максимумов (100), (101), (102) и (110) на дифрактограммах образцов, созданных методом магнетронного распыления.

Проведенные исследования шероховатости поверхности пленок на сканирующем зондовом микроскопе Solver PRO (фирмы НТ-МДТ) показали высокое структурное совершенство пленки, синтезированной методом лазерной абляции как на подложке из кварца, так и на подложке из $\mathrm{LiTaO}_{3}$. Шероховатость пленки $\mathrm{ZnO}$ на кварцевой подложке не превышала 80.0 нм, а шероховатость пленки $\mathrm{ZnO}$, созданной на сегнетоэлектрической подложке из $\mathrm{LiTaO}_{3}$, не превышала 97.0 нм.

Для определения наличия в пленке оксида цинка ловушек, обладающих одновременно электрически и оптически активными свойствами, а также оценки величин энергии активации и частотного фактора были проведены исследования спектральных зависимостей токов фотопроводимости (рис. 2). Изучение процессов фотопроводимости проводилось на установке, описанной в работе [9]. Установка состояла из пикоамперметра/источника напряжения Keithley 6487 и спектрометрического модуля, состоящего из источника излучения (ксеноновая лампа с кварцевым конденсором) и монохроматора МДР-41. Диапазон измеряемых токов составлял $0.01 \mathrm{HA}-20$ мкА. Измерения проводились 
при комнатной температуре. Сканирование по длине волны в спектральной полосе 300-800 нм проводилось по точкам, со скоростью $5.0 \mathrm{HM} / \mathrm{c}$. Время накопления токового сигнала в каждой точке составляло $10.0 \mathrm{c}$, что позволило исключить влияние переходных токов на кривые спектральной зависимости фотопроводимости. Электроды из аквадага были нанесены на концы полосок из оксида цинка. Измерения проводились в топологии планарного фоторезистора.

Кривые спектральных зависимостей тока фотопроводимости исследуемых структур представлены на рис. 2: кривая 1 соответствует фототоку, измеренному в пленке $\mathrm{ZnO}$, нанесенной на горячую подложку из танталата лития, кривая 2 соответствует фототоку, измеренному в пленке оксида цинка, нанесенной на холодную подложку из танталата лития, а кривая 3 - для фототока в пленке, нанесенной на поверхность кварцевой пластины. Спектральная зависимость фототока, измеренного в пленке оксида цинка, сформированной на горячей подложке из $\mathrm{LiTaO}_{3}$, имеет несимметричный относительно положения максимума колоколообразный вид кривой: нарастание фототока происходит быстрее, чем спад фототока. Максимум кривой фототока находится на 394 нм и равен 16.7 мкА. Спектральная зависимость фототока после максимума имеет широкий хвост, спадающий в длинноволновой области от 400 до 525 нм.

Спектральная зависимость тока фотопроводимости для пленки $\mathrm{ZnO}$, созданной на кварцевой подложке, также представляет собой вид сложной кривой, состоящей из нескольких областей. Область нарастания фототока состоит из двух сублинейных участков с сильно различающимися скоростями увеличения тока: в спектральной полосе 300-320 нм скорость нарастания превышает в 2.3 раза скорость роста тока в спектральной полосе 325-375 нм. Область максимальных значений фототока находится в спектральной полосе $377-390$ нм, пик тока фотопроводимости - на 385 нм, максимальное значение тока фотопроводимости составляет 1.08 мкА. Такое поведение зависимости тока фотопроводимости может быть объяснено тем, что в пленке $\mathrm{ZnO}$ на кварце имеется несколько типов оптически активных ловушек со значительно различающимися концентрациями и энергией активации, которые в процессе сканирования по спектру вовлекаются в процесс фотопроводимости.

Спектральные зависимости фототока, обусловленного неравновесной фотогенерацией носителей заряда в слое оксида цинка и их дальнейшего переноса между электродами, описываются интегральным уравнением Фредгольма І-го рода. Как известно, нахождение решения интегрального уравнения Фредгольма І-го рода относится к классу некорректных задач по Адамару. Одним из методов нахождения решения некорректных задач является метод регуляризации Тихонова-Лаврентьева. В этой связи нами для восстановления вида зависимости распределения ловушек по энергии активации $G(E)$ было решено методом регуляризации уравнение
Таблица 1. Энергия активации и величина частотного фактора для слоя оксида цинка, сформированного на поверхности кварцевой пластины

\begin{tabular}{r|c|c}
\hline № & $\begin{array}{c}\text { Энергия } \\
\text { активации, эВ }\end{array}$ & $\begin{array}{c}\text { Величина частотного } \\
\text { фактора, } \mathrm{c}^{-1}\end{array}$ \\
\hline 1 & 3.1 & $2.3 \cdot 10^{-7}$ \\
2 & 3.0 & $5.8 \cdot 10^{-7}$ \\
3 & 2.9 & $7.1 \cdot 10^{-5}$ \\
4 & 2.55 & $4.3 \cdot 10^{-8}$ \\
5 & 2.36 & $2.2 \cdot 10^{-8}$ \\
6 & 1.95 & $4.5 \cdot 10^{-7}$ \\
7 & 1.82 & $8.2 \cdot 10^{-7}$ \\
8 & 1.23 & $1.4 \cdot 10^{-8}$ \\
9 & 0.98 & $3.2 \cdot 10^{-7}$ \\
10 & 0.96 & $3.6 \cdot 10^{-8}$ \\
11 & 0.93 & $7.5 \cdot 10^{-8}$ \\
12 & 0.9 & $3.6 \cdot 10^{-8}$ \\
13 & 0.87 & $2.6 \cdot 10^{-7}$
\end{tabular}

Фредгольма I-го рода (описывающее процессы неравновесной фотогенерации и транспорта носителей заряда), с учетом наличия случайной и систематических ошибок во входных данных. В результате численного решения были получены зависимости $G(E)$ распределения ловушек по энергии активации в $\mathrm{ZnO}$, сформированном на поверхности кварцевой пластины, на поверхности предварительно нагретой пластины из тантала лития и в слое оксида цинка, созданного на поверхности пластины из тантала лития без предварительного нагрева. В слое оксида цинка, сформированном на поверхности кварцевой пластины, неравновесные фотостимулированные носители генерируются с моноэнергетических глубоких ловушек, энергия активации и величина частотного фактора которых представлены в табл. 1 .

В слое оксида цинка, сформированном на поверхности предварительно нагретой пластины из танталата лития, фотостимулированные носители также генерируются с моноэнергетических глубоких ловушек, энергия активации и величина частотного фактора которых представлены в табл. 2.

В слое оксида цинка, который был создан на поверхности пластины из танталата лития без предварительного нагрева, фотостимулированные носители также генерируются с моноэнергетических глубоких ловушек, энергия активации и величина частотного фактора которых представлены в табл. 3

Согласно анализу литературных данных, ловушки, энергия активации которых может иметь такие значения, скорее всего, соответствуют присутствующим в объеме оксида цинка вакансиям кислорода или цинка $[15,16,18]$. Как известно, вакансии кислорода в оксиде цинка могут находиться в трех различных зарядовых состояниях: нейтральном, однократно ионизированном, двукратно ионизированном. Однократно ионизированные вакансии 
Таблица 2. Энергия активации и величина частотного фактора для слоя оксида цинка сформированного на поверхности предварительно нагретой пластины из танталата лития

\begin{tabular}{r|c|c}
\hline № & $\begin{array}{c}\text { Энергия } \\
\text { активации, эВ }\end{array}$ & $\begin{array}{c}\text { Величина частотного } \\
\text { фактора, } c^{-1}\end{array}$ \\
\hline 1 & 3.27 & $4.3 \cdot 10^{-7}$ \\
2 & 3.19 & $5.7 \cdot 10^{-7}$ \\
3 & 2.9 & $1.1 \cdot 10^{-5}$ \\
4 & 2.58 & $3.3 \cdot 10^{-8}$ \\
5 & 2.27 & $6.2 \cdot 10^{-8}$ \\
6 & 1.97 & $2.5 \cdot 10^{-7}$ \\
7 & 1.89 & $7.2 \cdot 10^{-7}$ \\
8 & 1.84 & $3.4 \cdot 10^{-8}$ \\
9 & 0.98 & $6.2 \cdot 10^{-8}$ \\
10 & 0.96 & $1.5 \cdot 10^{-8}$ \\
11 & 0.93 & $5.2 \cdot 10^{-8}$ \\
12 & 0.74 & $1.7 \cdot 10^{-7}$ \\
13 & 0.65 & $4.3 \cdot 10^{-7}$
\end{tabular}

Таблица 3. Энергия активации и величина частотного фактора для слоя оксида цинка сформированного на поверхности пластины танталата лития без предварительного нагрева

\begin{tabular}{|c|c|c|}
\hline № & $\begin{array}{c}\text { Энергия } \\
\text { активации, эВ }\end{array}$ & $\begin{array}{c}\text { Величина частотного } \\
\text { фактора, } \mathrm{c}^{-1}\end{array}$ \\
\hline 1 & 3.28 & $3.3 \cdot 10^{-6}$ \\
\hline 2 & 3.18 & $4.3 \cdot 10^{-6}$ \\
\hline 3 & 2.9 & $3.1 \cdot 10^{-5}$ \\
\hline 4 & 2.67 & $4.3 \cdot 10^{-7}$ \\
\hline 5 & 2.58 & $5.2 \cdot 10^{-6}$ \\
\hline 6 & 2.27 & $8.1 \cdot 10^{-6}$ \\
\hline 7 & 1.93 & $2.2 \cdot 10^{-7}$ \\
\hline 8 & 1.84 & $8.4 \cdot 10^{-6}$ \\
\hline 9 & 0.98 & $5.2 \cdot 10^{-8}$ \\
\hline 10 & 0.96 & $3.5 \cdot 10^{-8}$ \\
\hline 11 & 0.93 & $1.2 \cdot 10^{-8}$ \\
\hline 12 & 0.75 & $3.7 \cdot 10^{-6}$ \\
\hline 13 & 0.68 & $2.3 \cdot 10^{-7}$ \\
\hline
\end{tabular}

кислорода имеют энергии активации 0.93, 0.96, 1.82, 1.84 эВ. Двукратно ионизированные вакансии кислорода имеют следующие энергии активации $0.98,2.27,2.58$, $2.9,3.1$ эВ. Также в процессах фотостимулированной генерации неравновесных носителей заряда принимают участие доноры [15-18]. Благодаря участию этого типа ловушек в фотостимулированных процессах происходит последовательная передача энергии при фотоионизации.

В этой связи в процессы фотопроводимости в слое оксида цинка, нанесенного на поверхность танталата лития, вносят свой вклад и глубокие ловушки, энергия активации которых находится среди значений $3.28,3.27$, $3.19,3.18$ эВ и которые присутствуют сугубо в слое оксида цинка, нанесенного на поверхность танталата лития. Для оксида цинка, нанесенного на горячую подложку из танталата лития, глубокие ловушки, участвующие в транспорте фотостимулированных носителей заряда, имеют энергию активации 3.28 и 3.19 эВ. Для оксида цинка, сформированного на холодной подложке из танталата лития, глубокие ловушки имеют энергии активации 3.27 и 3.18 э. Различие между ними на величину в 0.1 эВ, скорее всего, обусловлено морфологией оксида цинка, которая зависит от режима формирования на подложке (от температуры подложки). Эти глубокие ловушки, принимающие участие в генерации неравновесных носителей заряда и в токовом транспорте, имеют частотный фактор $\sim 10^{-6} \mathrm{c}^{-1}$, что позволяет предположить их нахождение в оксиде цинка на межфазном интерфейсе полупроводник-сегнетоэлектрик. Кроме того, энергия квантов УФ и видимого диапазона была выбрана заведомо меньшей высоты потенциального барьера полупроводник-сегнетоэлектрик. Поэтому можно пренебречь надбарьерными механизмами токового транспорта при фотостимулированной генерации неравновесных носителей заряда в структуре полупроводник-сегнетоэлектрик.

\section{4. Заключение}

Метод импульсной лазерной абляции мишени из порошка ZnO марки OCЧ DPSS-лазером, в режиме генерации гигантских импульсов, позволяет создавать на поверхности танталата лития тонкие пленки $\mathrm{ZnO}$ с высоким структурным совершенством. Об этом свидетельствуют наличие интенсивных рефлексов (001) и (002) на дифрактограммах исследуемых пленок.

Во всех исследуемых образцах обнаружено присутствие однократно и двукратно ионизированных вакансий кислорода. В образцах оксида цинка, сформированного на поверхности танталата лития, обнаружены глубокие ловушки, которые локализованы на межфазном интерфейсе полупроводник-сегнетоэлектрик.

Структуры $\mathrm{ZnO}-\mathrm{LiTaO}_{3}$ по совокупности своих структурных и фотоэлектрических свойств могут быть использованы для создания планарных фотоэлектрических, акустоэлектронных и акустооптических приборов, работающих в УФ и видимом диапазонах спектра.

\section{Финансирование работы}

Работа частично поддержана Министерством науки и высшего образования Российской Федерации (проект „Госзадание“, грант № FSEE-2020-0005).

\section{Конфликт интересов}

Авторы заявляют, что у них нет конфликта интересов. 


\section{Список литературы}

[1] W.Z. Xu, Z.Z. Ye, Y.J. Zeng, L.P. Zhu, B.H. Zhao, L. Jiang, J.G. Lu, H.P. He, S.B. Zhang. Appl. Phys. Lett., 88, 173506 (2006).

[2] C.L. Wei, Y.E. Chen, C.C. Cheng. Thin Sol. Films, 518, 3059 (2010).

[3] Y.K. Chembo, D. Brunner, M. Jacquot, L. Largerl. Rev. Mod. Phys., 91 (3), 035006 (2019).

[4] В.А. ривченко, Д.В. Лопаев, В.В. Пащенко, В.Г. Пирогов, А.Т. Рахимов, Н.В. Суетин, А.С. Трифонов. ЖТФ, 78 (8), 107 (2008).

[5] Т.В. Бланк, Ю.А. Гольденберг. ФТП, 37 (9), 1035 (2003).

[6] Zh. Wen, Ch. Li, D. Wu, A. Li, N. Ming. Nature Materials, 12, 617 (2013).

[7] Л.В. Григорьев, А.А. Семенов, Я.Б. Егорова, Н.А. Быков. Опт. и спектр., 127 (12), 986 (2019).

[8] Л.В. Григорьев, А.А. Семенов, И.А. Морозов, Н.С. Журавлев ФТП, 54 (3), 232 (2020).

[9] L.V. Grigoryev, A.F. Kraycko, A.V. Mikhailov, V.G. Nefedov, O.V. Shakin. Adv. Mater., Proc. Int. Conf. on „Physics and Mechanics of New Materials and their Applications", PHENMA-17, v. 207, chap. 19, p. 239 (2017).

[10] О.Г. Вендик, В.Ф. Горин. Корпускулярно-фотонная технология (М., Высш. шк., 1984) с. 239.

[11] W. Prellier, A. Fouchet, B. Mercey, Ch. Simon, B. Raveau. Appl. Phys. Lett., 82, 3490 (2003).

[12] S. Hermann, T. Dezhindar, H. Harder, R. Brendel. J. Appl. Phys., 108, 114514 (2010).

[13] А.А. Русаков. Рентгенография металлов (М., Атомиздат, 1977) c. 480.

[14] P. Narin, E. Kutlu, G. Atmaca, A. Atilgan, A. Yildiz, S. Lisesivdin. Optik, 168, 86 (2018).

[15] U. Helmensonn, M. Latemann, J. Bohlmark, A.P. Ehiasarian, J.T. Gudmudsson. Thin Sol. Films, 513 (1-2), 1 (2006).

[17] B.D. Yao, V.F. Chang, F. Wang. Appl. Phys. Lett., 81, 757 (2002).

[18] D.M. Bagnal, Z. Chen, T. Yao. Appl. Phys. Lett., 73, 1038 (1998).

Редактор А.Н. Смирнов

\section{Structural and photoelectric properties the thin film $\mathrm{ZnO}$ on $\mathrm{LiTaO}_{3}$ substrate}

\author{
L.V. Grigoryev ${ }^{1,2}$, A.A. Semenov ${ }^{2}$, A.V. Mikhailov ${ }^{3}$ \\ ${ }^{1}$ St. Petersburg State University, \\ 199034 St. Petersburg, Russia \\ ${ }^{2}$ St. Petersburg State Electrotechnical University „LETI“, \\ 197022 St. Petersburg, Russia \\ ${ }^{3}$ Vavilov Research Institute, \\ 199054 St. Petersburg, Russia
}

Abstract The results of the study of the structural and photoelectric properties of the $\mathrm{ZnO}-\mathrm{LiTaO}_{3}$ thin-film structure are presented. The results $X$-ray structural analysis and results atomicforce microscopy of the surface zinc oxide thin films synthesized on a single-crystal lithium tantalite substrate and on a KU-1 quartz substrate are presented. The spectral dependence of photoconductivity in the thin film structure of $\mathrm{ZnO}-\mathrm{LiTaO}_{3}$ and the structure of $\mathrm{ZnO}$-quartz in the ultraviolet and visible spectral ranges are presented. 